\title{
Numerical investigation of initial crack growth in composite laminates under tension
}

\author{
Evgeny Dubovikov ${ }^{1,}$, Alexander Shanygin ${ }^{1}$ and Dmitry Vedernikov ${ }^{1}$ \\ ${ }^{1}$ Central Aerohydrodynamic Institute, Russian Federation
}

\begin{abstract}
The simplified automated strength model of a fragment of composite laminate at microlevel based on the finite elements (FE) method is offered. The model allows investigating the growth of microcracks which arise in the resin in monolayers, orthogonal to a direction of external tensile force. On the basis of automated strength FE model of a fragment of composite laminate and the method of reduction of stiffness characteristics of the resin, the scenario of growth of primary destructions at the microlevel is offered and proved. The scenario is confirmed with experimental investigations of composite samples under tension with registration of acoustic emission. In the work, the dependences of decrease of strength characteristics of composite laminates are obtained as functions of characteristics of resin, angles of orientation of monolayers, volume ratio of fibres in a composite laminate.
\end{abstract}

\section{Introduction}

Aircraft structures made of composite laminates, based on carbon reinforcing fibres, are considered as alternative to conventional primary metal structures for increasing weight efficiency of aircraft structures. However, high sensitivity of composite laminates to impacts and climatic factors, their fragility and complex character of internal stress-strain state do not allow realising potential of high-strength carbon fibres and providing high weight efficiency of composite structures. The specified drawbacks are caused by a presence of plural stress concentrations at the microlevel, leading to occurrence and propagation of primary destructions (microcracks) in resin and the subsequent degradation of strength characteristics of composite laminates while in service.

Analysis of experimental and numerical investigations of strength of composite structures [1-8] has shown that in multi-layered composite laminates, even at low values of external tensile forces, there are multiple zones with high level of stress concentration in resin in layers, orthogonal to the direction of external force (fig. 1). The nature of occurrence of such stress concentrations is caused by the topology of composite laminates, and the character of propagation of the cracks, arising in zones of the concentrations, is caused by low strength characteristics of resin.

\footnotetext{
${ }^{*}$ Corresponding author: evgeny.dubovikov@tsagi.ru
} 


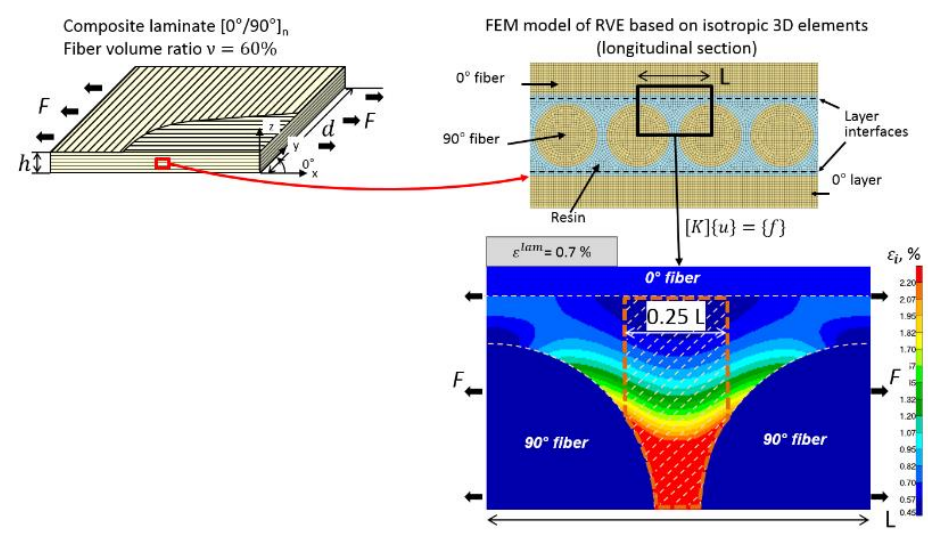

Fig. 1. Picture of stress-strain state (equivalent strains under tension) of resin in a layer of composite laminate, orthogonal to the direction of external force.

Unfortunately, existing strength criteria do not allow providing long-term strength at designing highly loaded aircraft structures, subjected to the influence of climatic factors and impacts, without considerable losses in weight efficiency.

For designing primary composite aircraft structures with high weight efficiency, meeting the requirements of long operation, it is necessary to have the reliable strength criteria considering occurrence of microcracks, their propagation and relation of these processes with strength of aircraft structure. Such strength criteria can be developed only on the basis of the extensive numerical and experimental investigations of strength of composite laminates, including investigations at microlevel. The given work is focused on the first steps in solving this problem.

\section{Method of numerical modelling composite laminates}

The first step to develop engineering strength criteria for composite laminates is investigation of the process of occurrence and propagation of cracks in resin at microlevel under the influence of external mechanical loading, and also investigation of the influence of microcracks on mechanical characteristics of composite laminate.

In the work a simplified automated strength model of a fragment of composite laminate (RVE, representative volume element) at microlevel on the basis of finite elements (FE) method is offered. The model allows investigating propagation of microcracks arising in resin in monolayers, orthogonal to a direction of external tensile force, and also transition of microcracks from microlevel to interlaminar level. The FE model of an RVE has been created with the following basic assumptions:

- a fiber and resin are homogeneous media,

- a fiber and resin interact on all area of their contact,

- a fiber is a direct cylinder with circular cross-section,

- fibers in a monolayer lie in one plane, are parallel to each other and equidistant.

The main parameters defining the structure of FE model of an RVE are: fiber volume ratio, diameter of a fiber, angles of orientation of monolayers, elastic and strength characteristics of a fiber and resin.

The offered FE model of an RVE includes 3 groups of the finite elements, modelling accordingly reinforcing fibers, resin and the interphase layer (fig. 2). The model of an RVE consists of 3 monolayers (two longitudinal and one at an angle to the direction of tension force) and several fibers in each monolayer. 
In frames of the offered FE model of an RVE the microcracks can propagate through finite elements of resin or interphase layer. This process is modelled by reduction of stiffness parameters of FEs which have reached the allowable value of equivalent strains.

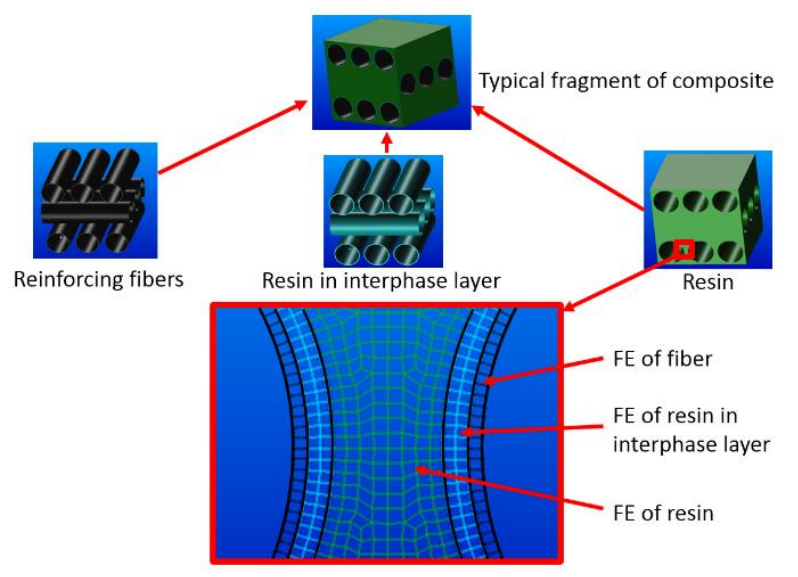

Fig. 2. Model of RVE of composite laminate.

For estimation of degree of microcracks propagation a "relative crack size" term is introduced, which is determined by the relation of length of the microcrack growing along a circle of cross-section of a fibre, to a quarter of length of this circle. It is supposed that the microcrack propagates by "the front" along fibres in orthogonal monolayers. Thus, the level of microcracks propagation of $100 \%$ corresponds to a condition at which fibres in an orthogonal layer have completely lost a contact with resin. This state is called "debonding".

The modelling procedure of microcracks propagation under the influence of external tensile force is based on an iterative procedure of calculation of a linear stress-strain state with reduction of stiffness of finite elements on each iteration:

$$
\begin{aligned}
& E_{i+1}^{k}=E_{i}^{k} \cdot \phi_{i}^{k}\left(\varepsilon_{i . r}^{k}(i)\right), \\
& G_{i+1}^{k}=G_{i}^{k} \cdot \phi_{i}^{k}\left(\varepsilon_{i . r}^{k}(i)\right),
\end{aligned}
$$

where $i$ - iteration number, $k$ - number of a final element,

$\phi_{i}^{k}\left(\varepsilon_{i . r}^{k}(i)\right)$ - reduction coefficients of elasticity modules, depending on equivalent strains in resin,

$$
\phi_{i}^{k}\left(\varepsilon_{i . r}^{k}(i)\right)=\left\{\begin{array}{c}
0.01, \varepsilon_{i . r}^{k}(i) \geq \varepsilon_{a l}^{r} \\
1, \varepsilon_{i . r}^{k}(i)<\varepsilon_{a l}^{r}
\end{array}\right.
$$

Thus, while microcracks propagate, those finite elements, in which allowable value of strains has been reached, are switched off from work of a composite laminate.

\section{Results of strength analysis of composite laminate}

In frames of this work, a research on determination of the dependence of strength parameters of composite laminates on the basic design parameters was carried out. Laminates on the basis of the T700 carbon fibres and the M21 resin with various stacking sequences were considered.

Fig. 3 shows the results of the numerical analysis of stress-strain state and microcracks propagation in an orthogonal composite laminate under tension. 


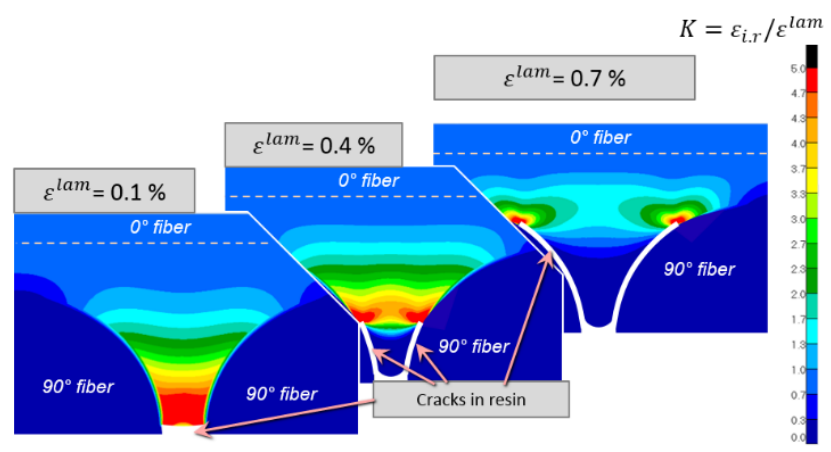

Fig. 3. Computer modelling of microcracks propagation in resin.

The figure shows that in the orthogonal layers in resin between fibres there are stress/strain concentrations leading to occurrence of microcracks. The microcracks propagate along a cross-section of the fibres while the external tensile force is increased.

The dependence of the "relative crack size" on the strain value of the composite laminate in the direction of the tensile force, and also influence of the microcracks on elastic characteristics of the laminate are shown accordingly on fig. 4 and 5.

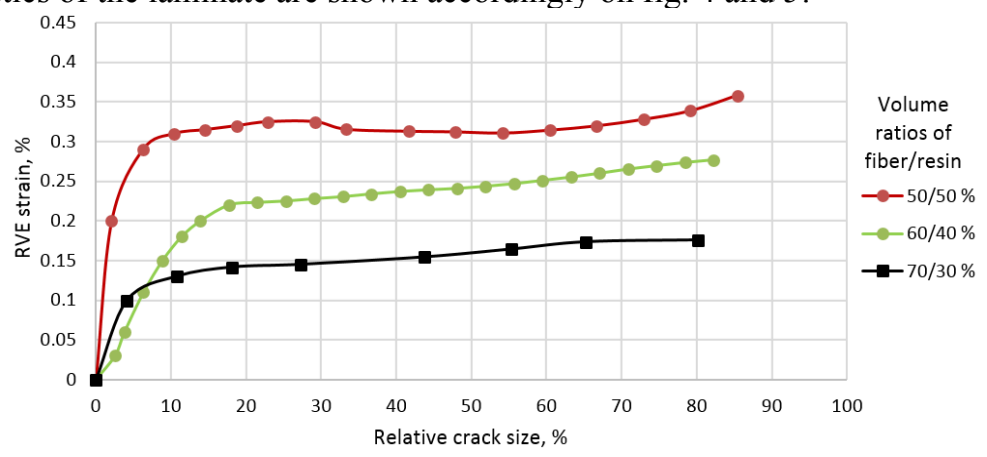

Fig. 4. The dependence of the "relative crack size" on the strain value of the composite laminate in the direction of the tensile force.

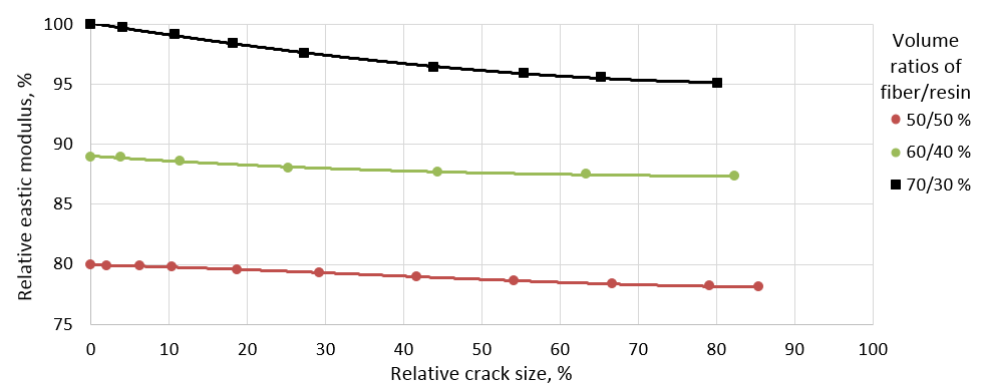

Fig. 5. The influence of the microcracks on elastic characteristics of the composite laminate.

The numerical investigations have shown that the solutions, obtained on the basis of the offered FE model, despite a number of simplifications, have allowed obtaining a picture of occurrence and propagation of initial internal damages in a composite laminate. The numerical results qualitatively and quantitatively coincide with the results of experimental investigations with application of acoustic emission (AE) method [3] (fig. 6). 


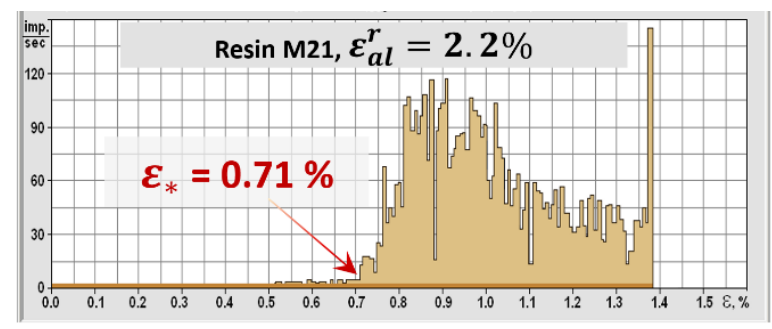

Fig. 6. Acoustic emission of a sample of composite laminate under tension.

The data of acoustic emission (AE), obtained during tension of a quasi-isotropic composite laminate with M21 resin (with allowable strain of $\varepsilon_{\text {al }}^{r} \approx 2 \%$ ), are shown on the diagram (fig. 6). It is obvious that for this composite laminate AE (illustrating destruction process) includes 3 following stages:

- small strains under $0.1 \%$ when practically there is no acoustic emission, and the laminate can be considered as almost intact,

- strains from $0.1 \%$ to $0.7 \%$ when microcracks appear and propagate between fibres, orthogonal to the direction of the external tensile force, but degradation of interlaminar contacts is still insufficient for delamination,

- strains exceeding the value of $0.7 \%$ when the laminate receives local delaminations, leading to destruction.

One of the most important results, obtained in this work, is obtaining and substantiation of the simple and confident relations connecting the level of stress concentrations in resin with the global design parameters of a laminate.

The given relations are used for formation of the simple and reliable deformation strength constraints of composite laminates on the basis of the relation $\varepsilon_{\mathrm{al}}^{\text {lam }}=\varepsilon_{\mathrm{al}}^{r} / K$, where $\varepsilon_{\mathrm{al}}^{\text {lam }}$ allowable tensile strains of the laminate, $\varepsilon_{\mathrm{al}}^{r}$-allowable strains of resin, $K$ - factor of stress concentrations in resin in the monolayer at microlevel.

\section{Conclusions}

In the work the method of strength analysis of a composite laminate on the basis of the finite elements method, taking into account occurrence and propagation of microcracks in resin, is offered. Despite a number of simplifications, the offered method has shown good conformity to the experimental data, obtained during tension of composite laminated samples with registration of their acoustic emission.

However, the offered method at the given stage is applicable only for the analysis of the initial stage of microcracks propagation in a composite laminate. The further development of the numerical method of modelling is supposed in order to carry out strength analysis of a composite laminate taking into account the further propagation of the microcracks and transition of their sizes from microlevel to mesolevel (delaminations).

This work was supported by the Subsidy of Ministry of Education and Science of the Russian Federation, Agreement \#14.628.21.0009, project identification number RFMEFI628180009.

\section{References}

1. Ullah, Z. Three-dimensional nonlinear micro/meso-mechanical response of the fibrereinforced polymer composites / Z. Ullah, L. Kaczmarczyk, C.J. Pearce // Composite Structures. - 2017. - № 161. - pp. 204-214. 
2. Ernst, G. Multiscale progressive failure analysis of textile composites / G. Ernst, M. Vogler, C. Hühne, R. Rolfes // Composites Science and Technology. - 2010. - № 70. pp. 61-72.

3. V.P. Fomin, A.V. Chernov, A.N. Shanygin Strength Criteria Development for Composite Structures Basing on Solutions Superposition for Models of Different Levels // Proceedings of the 28th Congress of the International Council of the Aeronautical Sciences (ICAS 2012). - 2012.

4. Pascault, J.-P. Epoxy polymers. New materials and innovations / J.-P. Pascault, R. Williams. - WILEY-VCH Verlag GmbH \& Co. KGaA, Weinheim, 2010.

5. Vasiliev, V.V. Composite materials in aviation and space technology / V.V. Vasiliev // All materials. Encyclopedic handbook. - M.: 2012.

6. Micromechanics of composites / G.A. Vanin. - Kiev: Naukova dumka, 1985.

7. Strength of polymers and composite materials / A.K. Malmeister, V.P. Tamuzh, G.A. Teters. - Riga: Zinatie, 1980.

8. Mechanics of composite materials and structure elements. Volume 1. Mechanics of materials / A.N. Guz, L.P. Horoshun, G.A. Vanin - Kiev: Naukova dumka, 1982. 